\title{
Stereotactic neurosurgical treatment options for craniopharyngioma
}

\section{Michael Trippel * and Guido Nikkhah}

Section of Stereotactic and Functional Neurosurgery, University Hospital Freiburg, Freiburg, Germany

Edited by:

Hermann Lothar Mueller, Klinikum

Oldenburg gGmbH, Germany

\section{Reviewed by:}

Philippe Chanson, Université

Paris-Sud, France

Laurence Katznelson, Stanford

University, USA

*Correspondence:

Michael Trippel, Division of

Stereotactic and Functional

Neurosurgery, University Hospital

Freiburg, Breisacher Strasse 64,

79106 Freiburg, Germany.

e-mail: michael.trippel@

uniklinik-freiburg.de
Craniopharyngioma are the most common non-glial tumors in childhood. The results of different studies indicate that radical excision surgery is not an appropriate treatment strategy for childhood craniopharyngioma with hypothalamic involvement. Stereotactic neurosurgery provides save, minimal invasive and cost-efficient options in the treatment of childhood craniopharyngioma. In this review a summary of the contribution of the stereotactic neurosurgery in the interdisciplinary treatment regime of childhood craniopharyngioma will be given and discussed in detail.

Keywords: stereotactic neurosurgery, craniopharyngioma, stereotactic biopsy, internal drainage, cyst puncture, childhood craniopharyngioma, minimal invasive, ventriculocystostomy

\section{INTRODUCTION}

Craniopharyngiomas are the most common non-glial tumors with an incidence of $0.5-1.0$ per million new patients per year, of which $30-50 \%$ occur in childhood. In children, they are often of the adamantinomatous type with cyst formations and are frequently associated with a mutation of the beta-catenin gene (Müller, 2010). These benign tumors are located in the sellar and parasellar regions and are typically semisolid, cystic, and calcifying. Compression or infiltration of the surrounding structures, such as the optic chiasm, hypothalamus, and the floor of the third ventricle, is common.

Over the last 40 years there exists an open-ended controversy concerning the best treatment for craniopharyngioma. One group favors open surgery which is in many cases associated with increased morbidity. The other group proposes minimal-invasive procedures combined with subsequent radiotherapy to minimize risk and morbidity.

Due to the high variability in the appearance of these tumors the treatment strategy must be individually tailored to the patient. Important parameters for treatment planning are the volume of the solid part of the tumor, the presence and volume of cysts, its proximity and adhesion to the hypothalamus, the compression of optical structures, the overall neuro-ophthalmological, and endocrinological state.

Microsurgical resection should be preferred when the solid part of the tumor is large and space occupying and if there is a good chance for a total resection with low risk, especially of a hypothalamic syndrome. A similar approach is also valid for many intrasellar and transsphenoidally accessible tumors. In contrast, if the solid part of the tumor is small or if there is a substantial risk for a visual or endocrinological degradation or a hypothalamic syndrome an alternative interdisciplinary approach, including stereotactic procedures, should be considered (Ostertag et al., 2003).
The stereotactic approach can facilitate the histopathological diagnosis from a stereotactic serial biopsy obtained from the solid part of the tumor or from the wall of a cyst (Tilgner et al., 2005). Furthermore, in the case of cysts, this approach can be used to evacuate the cystic parts of the lesion by aspiration or perform an internal drainage (ventriculocystostomy) by the implantation of a catheter. Cyst evacuation results in decreased compression of the surrounding structures (optical pathway, hypothalamus) and reduction in the total volume of the lesion, which prepares it for a possible subsequent, small volume, fractionated, external radiotherapy (Schubert et al., 2009; Veeravagu et al., 2010).

Stereotactic procedures are applied under general anesthesia for children, whereas juveniles and adults are mostly treated using local anesthesia (Figure 1). Optimized planning of the stereotactic approach is accomplished on a stereotactic workstation (STP, Stryker-Leibinger, Freiburg, Germany or Precisis Plus, Inomed, Emmendingen, Germany; Figure 2) based on preoperatively acquired high resolution MRI (MP-Rage post contrast and T2 - Space, $1 \mathrm{~mm}$, transversal or longitudinal orientation, Avanto, Siemens, Germany,) and intraoperative computed tomography (1 or $2 \mathrm{~mm}$, transversal, Somatom Plus, Siemens, Germany) following stereotactic head fixation. Image fusion is performed, which allows stereotactic planning in any imaging modality with good visualization of the tumor, cysts, calcifications, optic pathway, hypothalamus, pituitary stalk, vessels, and nerves.

A small skin incision is performed $(\sim 12 \mathrm{~mm})$, followed by a stereotactically guided burr hole. A probe with $1.4 \mathrm{~mm}$ diameter is advanced to the cyst, and a biopsy is taken from the cyst's wall. Then, the content of the cyst is aspirated and the detritus is washed out by rinsing with body-temperature saline solution. The cyst is left either emptied or refilled with saline solution if a Rickham catheter is to be placed (either for inner drainage or with a subcutaneous reservoir for later transcutaneous punctures 

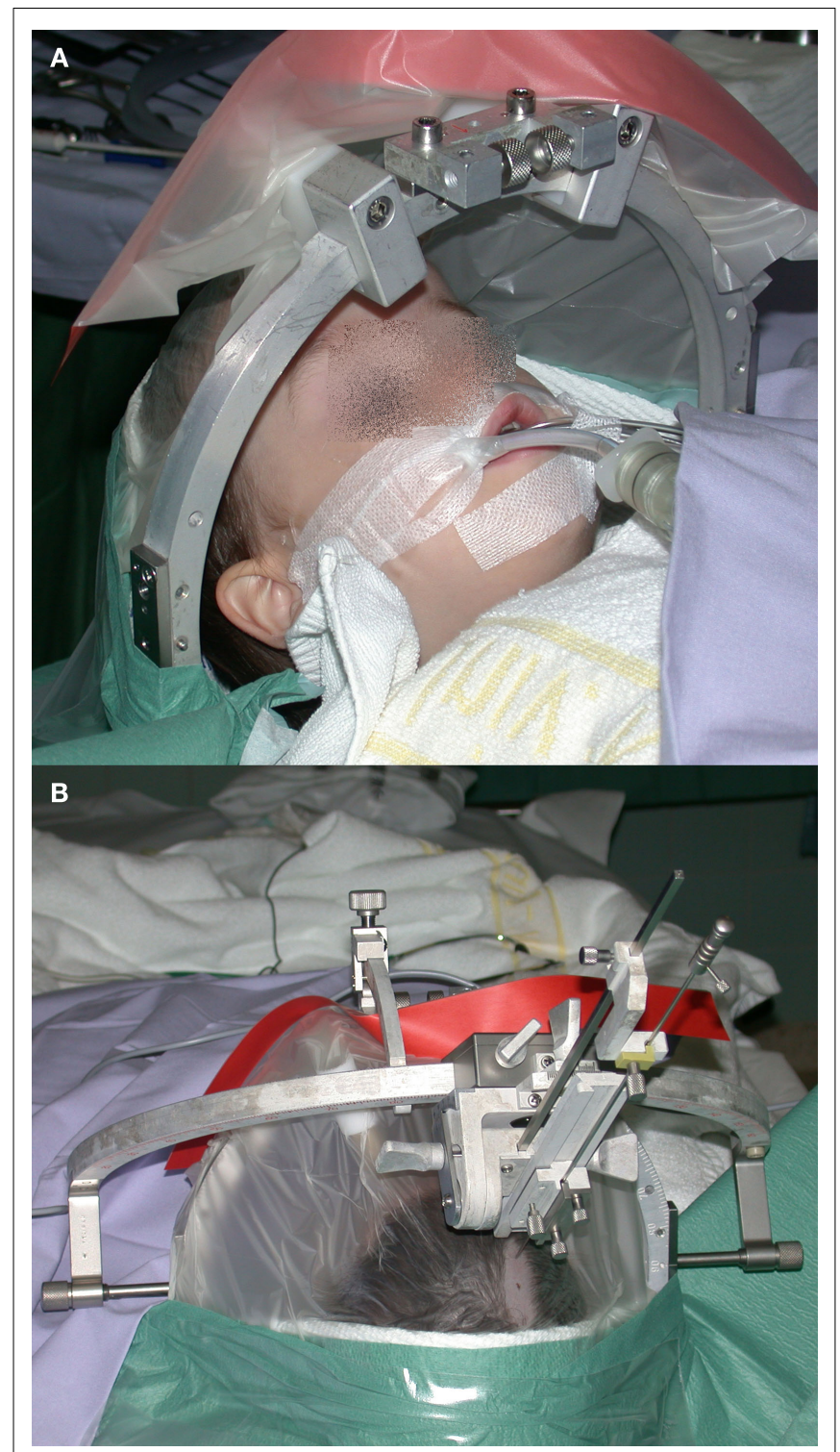

FIGURE 1 | (A) Child fixed in a stereotactic ring under general anesthesia in preparation for a stereotactic procedure. (B) Stereotactic aiming bow with a probe pointing to the shaved frontal entry point.

or treatment; Figure 3). The total time for the procedure is 60 $90 \mathrm{~min}$, followed by three to five in-patient days. Perioperative stress prophylaxis with hydrocortisone and optional single-shot antibiosis are applied. Following the procedure the liquid balance is documented in order to detect a temporary central diabetes insipidus, which would require Desmopressin substitution.

Before making a possible catheter implantation, a preliminary intraoperative histopathological diagnosis is obtained from a stereotactic biopsy taken from the cyst wall and is confirmed by the presence of cholesterol crystals in the cyst fluid.

The stereotactic procedure can be followed by a high precision, small volume, fractionated, external radiotherapy (30-40 Gy) depending on tumor growth, patient's age, and taking into account aspects like the possibility of genesis of secondary tumors in the low dose areas. For slow-growing craniopharyngioma there are arguments for protecting the developing brain of small children by delaying the time of irradiation to an age older than 6 years.

In the case of a tumor cyst recurrence following open resection and percutaneous irradiation some centers use local intracavitary irradiation by instillation of ${ }^{32} \mathrm{P}$ (Zhao et al., 2010), ${ }^{90} \mathrm{Y}$ (Blackburn et al., 1999; Kolumbán et al., 2011), colloidal ${ }^{186}$ Re (Derrey et al., 2008; Guo et al., 2010), or ${ }^{198} \mathrm{Au}$ (Tian et al., 1992) radioisotopes to induce fibrosis in order to suppress cyst fluid production. This is done by using stereotactically implanted catheters with subcutaneous reservoirs. Other groups describe the intracystic bleomycin therapy (Hukin et al., 2007) to induce cyst sclerosis with the intent to delay the need for surgery or radiation therapy for a few years. Serious or even fatal adverse events and long-term neurotoxicity have been reported for bleomycin use (Savas et al., 2000). For these intracavitary therapies the catheter-system must first be radiologically controlled after contrast injection before initiating therapy to avoid leakage or a connection to the ventricular system, which could induce serious, adverse side effects. Brachytherapy by the stereotactic implantation of temporary ${ }^{125} \mathrm{I}$ seeds in the solid part of a craniopharyngioma is also a possible treatment option (Barlas et al., 2000; Schubert et al., 2009).

Stereotactic neurosurgery can deliver several options for permanent internal drainage in a multidisciplinary approach following limited resection when recurrent cysts become space occupying, compress the optical pathway, or block the foramina Monroi: The stereotactic implantation of catheters connecting the ventricular system with the cyst (Schubert et al., 2009), the stereotactically guided endoscopic fenestration of cyst walls, or a combined stereotactic/endoscopic stent-assisted ventriculocystostomy (Berlis et al., 2006). In a series of eight patients, Pettorini et al. (2009) reports the use of neuroendoscopic positioning of intracystic catheters for treatment of craniopharyngioma as being safer than stereotactic approaches. This observation could not be confirmed in our series.

\section{CLINICAL SERIES}

From 1990 to 2010, 208 (total group) stereotactic procedures in patients with craniopharyngioma were performed in the Department of Stereotactic Neurosurgery in Freiburg. Seventy of these patients were under the age of 18 ("children," 33 male, 37 female), 138 were older ("adults," 67 male, 71 female). Eighty-three percent (children) and 10\% (adults) had treatment under general anesthesia. Sixty-one percent (children) and 60\% (adults) had a cyst puncture. Twenty-one percent (children) and 43\% (adults) underwent a stereotactic biopsy. Twenty-nine percent (children) and $15 \%$ (adults) underwent ventriculocystostomy by the implantation of a catheter. No procedure related lethality or permanent morbidity was observed with these patients. The patients were followed for $10.5 \pm 5.3$ years (median) and the $5 / 10$-years progression-free survival was $82 / 80 \%$, respectively. In the group of children, following stereotactic treatment, the patients' vision improved in $61 \%$, remained unchanged in $39 \%$, and the visual field ameliorated in $75 \%$ or remained stationary (25\%). While $6 \%$ experienced temporary minor visual degradation, which recovered within days, there was no permanent visual deficit due to stereotactic surgery. Following cyst drainage the endocrinological 


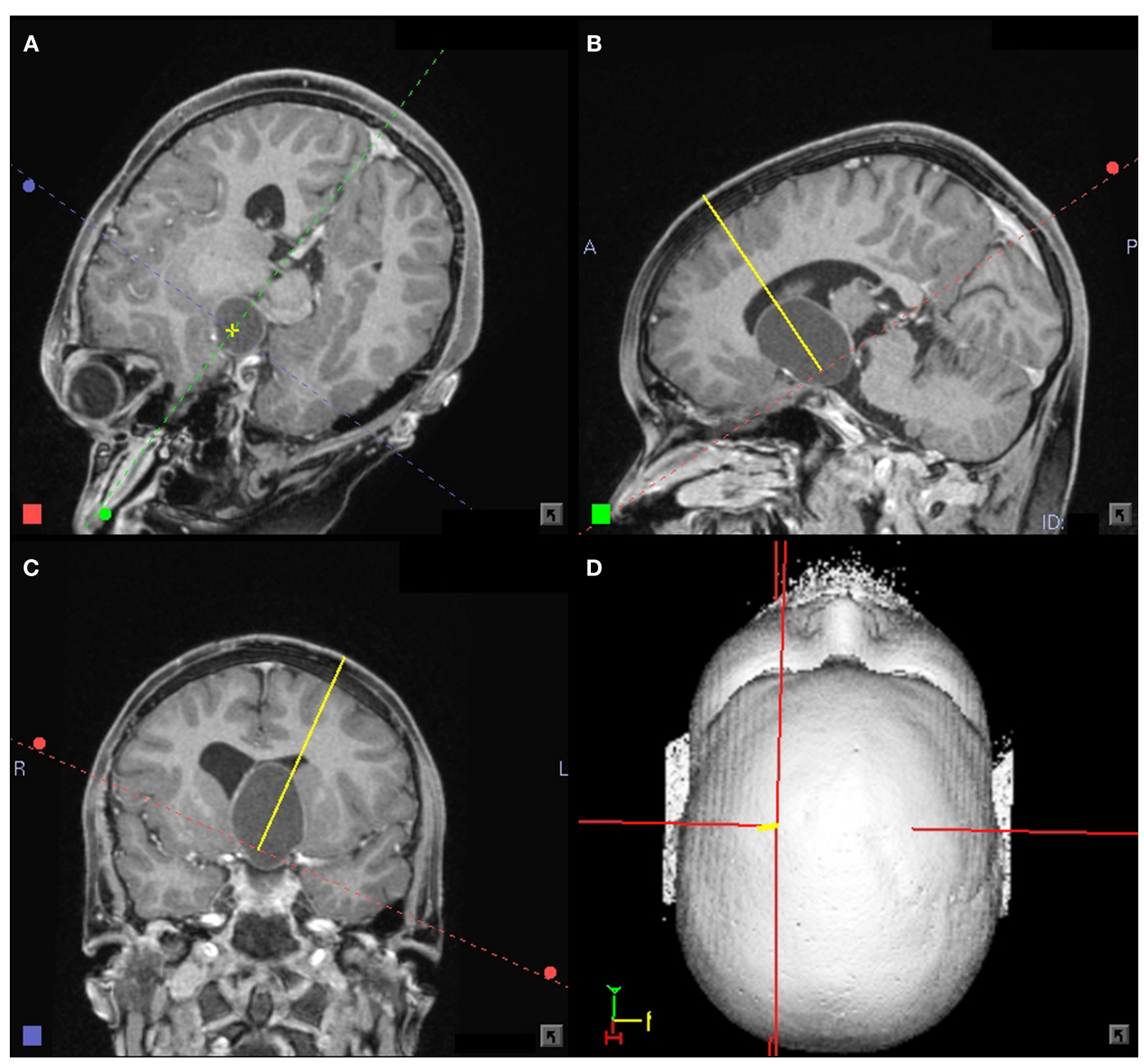

FIGURE 2 | (A-D) Eleven-year-old boy with a large craniopharyngioma cyst. Planning for a stereotactic biopsy and a cyst puncture with subsequent internal drainage showing the trajectory in an approach oriented view. Stereotactic planning system: STP4 - workstation (Stryker-Leibinger, Freiburg, Germany).

state remained unchanged in $93 \%$. Temporary treatment with Desmopressin was necessary in $6 \%$ of the patients due to diabetes insipidus. There was no permanent, additional endocrinological deficit observed due to the stereotactic procedure (Guthoff, 2000; Ostertag et al., 2003).

In a retrospective study Schubert et al. (2009) compared three groups of children ( $<18$ years of age) with craniopharyngioma $(n=32)$. The first group included patients treated with microsurgical resection. The second group underwent stereotactic cyst drainage, implantation of a Rickham catheter, and fractionated three-dimensional conformal multi-field radiotherapy with $54 \mathrm{~Gy}$ volume dose. The third group received various combined approaches. In this study, the 8.5-years of freedom from tumor recurrence was $24 \%$ in the resection group as compared to $71 \%$ for children with combined stereotactic and radio-therapeutic treatment $(p=0.05)$. There was no permanent postoperative morbidity related to stereotactic cyst puncture and drainage. Two children with preoperative visual impairment improved, the endocrinological state was constant. At last follow up, obesity was reported in four patients $(24 \%)$ in the resection group as compared to one patient $(14 \%)$ in the stereotactic cyst drainage group. All groups identified tumor recurrence as a criterion for a less favorable outcome. Combined stereotactic and radio-therapeutic treatment leads to good, long-term tumor control, and quality of life due to a low morbidity rate.

\section{DISCUSSION}

Stereotactic neurosurgery offers useful minimal-invasive treatment options in the interdisciplinary treatment regime of craniopharyngioma. These options must especially be considered if the solid part of the tumor is small, if there is a hypothalamic involvement, or if the probability for a complete resection is not favorable (Yaşargil et al., 1990). The results of the Kraniopharyngeom 2000 study indicate that radical excision surgery is not an appropriate treatment strategy for childhood craniopharyngioma with hypothalamic involvement (Müller, 2010, 2011; Steňo et al., 2011).

Childhood craniopharyngiomas are a rare tumor entity. Therefore, many clinical series reported in the literature comprise only a limited number of patients (Backlund et al., 1989, $n=42$; 


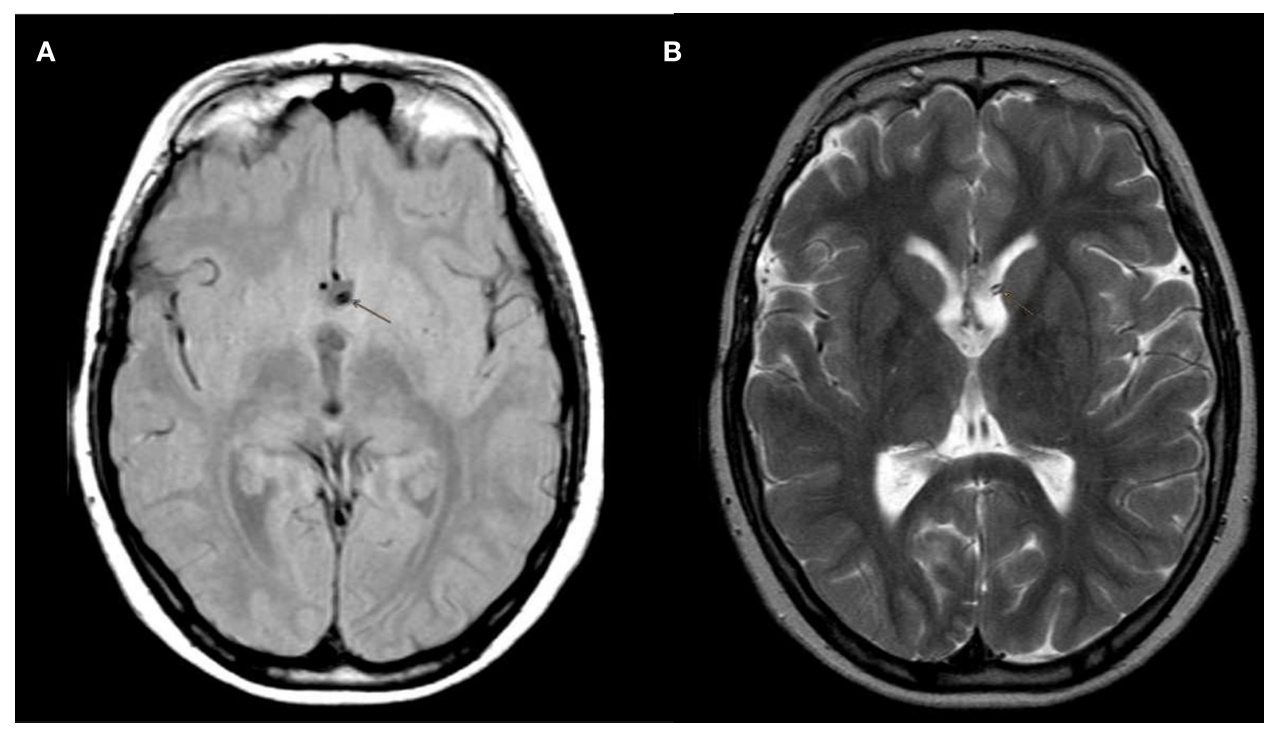

FIGURE 3 | (A,B) Postoperative MRI (T1 and T2 weighted) control showing the Rickham catheter for internal drainage ending in the shrunken hypothalamic cyst.

Hoffman et al., 1992, $n=50$; Schubert et al., 2009, $n=32$ ). In contrast, standardized prospective international multicenter studies, like Kraniopharyngeom 2007, which are based on a consensus of international brain tumor committees, applying identical datasets, can easily increase the cohort size, facilitate data evaluation, and can thereby advance scientific evidence (Müller, 2010).

Stereotactic biopsy can easily facilitate the histopathological diagnosis. The target volume can be significantly reduced by the evacuation and drainage of large cysts preceding fractionated external radiation therapy. Stereotactic neurosurgical methods provide safe, minimally invasive, and costefficient treatment options in the interdisciplinary treatment of

\section{REFERENCES}

Backlund, E. O., Axelsson, B., Bergstrand, C. G., Eriksson, A. L., Norén, G., Ribbesjö, E., Rähn, T., Schnell, P. O., Tallstedt, L., Sääf, M., and Thorén, M. (1989). Treatment of craniopharyngiomas-the stereotactic approach in a ten to twenty-three years perspective. I. Surgical, radiological and ophthalmological aspects. Acta Neurochir. (Wien) 99, 11-19.

Barlas, O., Bayindir, C., and Can, M. (2000). Interstitial irradiation for craniopharyngioma. Acta Neurochir. (Wien) 142, 389-395.

Berlis, A., Vesper, J., and Ostertag, C. (2006). Stent placement for intracranial cysts bycombined stereotactic/endoscopic surgery. Neurosurgery 59(Suppl. 2), ONS474-ONS479; discussion ONS479-ONS480.

Blackburn, T. P., Doughty, D., and Plowman, P. N. (1999). Stereotactic intracavitary therapy of recurrent cystic craniopharyngioma by instillation of 90yttrium. Br. J. Neurosurg. 13, 359-365.

Derrey, S., Blond, S., Reyns, N., Touzet, G., Carpentier, P., Gauthier, H., and Dhellemmes, P. (2008). Management of cystic craniopharyngiomas with stereotactic endocavitary irradiation using colloidal 186Re: a retrospective study of 48 consecutive patients. Neurosurgery 63, 1045-1052; discussion 1052-1053.

Guo, C. J., Wang, Y. C., Zhou, Z. H., Zhu, J. X., Li, Z. M., and Guo, C. L. (2010). Curative effect of stereotactic 186Re endocavitary irradiation on cystic craniopharyngioma. Zhonghua Zhong Liu Za Zhi 32, 548-550.

Guthoff, R. (2000). Ophthalmologische und Endokrinologische Befunde bei Primär Microchirurgisch und bei Stereotaktisch-Radiotherapeutisch Behandelten Patienten mit Kraniopharyngeomen. Dissertation. Medizinische Fakultät,

craniopharyngioma. The final approach should be tailored and discussed in an interdisciplinary and specialized tumor board in a dedicated and experienced center before starting the treatment.

\section{ACKNOWLEDGMENTS}

We thank Professor H. L. Mueller for his scientific advice and the IPSEN Company for their financial support of this publication. We thank Professor M. Schumacher and his team from the Department of Neuroradiology, University Hospital Freiburg for providing excellent MRI imaging. Valuable contribution to the final manuscript was made by Dr. Robert Kirch with his diligent text work and excellent editing.

Albert-Ludwigs-Universität, Freiburg.

Hoffman, H. J., De Silva, M. Humphreys, R. P., Drake, J. M., Smith, M. L., and Blaser, S. I. (1992). Aggressive surgical management of craniopharyngiomas in children. J. Neurosurg. 76, 47-52.

Hukin, J., Steinbok, P., Lafay-Cousin, L., Hendson, G., Strother, D., Mercier, C., Samson, Y., Howes, W., and Bouffet, E. (2007). Intracystic bleomycin therapy for craniopharyngioma in children: the Canadian experience. Cancer 109, 2124-2131.

Kolumbán, Z., Bálint, K., and Julow, J. (2011). Shrinkage dynamics of cystic craniopharyngeomas after Yttrium90 colloid brachytherapy. Ideggyogy. Sz. 64, 36-40.

Müller, H. L. (2010). Childhood craniopharyngioma - current concepts in diagnosis, therapy and follow-up. Nat. Rev. Endocrinol. 6, 609-618.
Müller, H. L. (2011). Consequences of craniopharyngioma surgery in children. J. Clin. Endocrinol. Metab. 96, 1981-1991.

Ostertag, C. B., Trippel, M., Unsöld, R., and Warnke, P. C. (2003) "Therapie der Kraniopharyngeome - Konservatives Vorgehen" in Aktuelle Neuropädiatrie 2002, ed. R. Krointhenberg (Nuremberg: Novartis Pharma Verlag), 43-48.

Pettorini, B. L., Tamburrini, G., Massimi, L., Caldarelli, M., and Di Rocco, C. (2009). Endoscopic transventricular positioning of intracystic catheter for treatment of craniopharyngioma. J. Neurosurg. Pediatr. 4, 245-248. [Technical note].

Savas, A., Erdem, A., Tun, K., and Kanpolat, Y. (2000). Fatal toxic effect of bleomycin on brain tissue after intracystic chemotherapy for a craniopharyngioma: case report. $\mathrm{Neu}$ rosurgery 46, 213-216; discussion 216-217. 
Schubert, T., Trippel, M., Tacke, U., van Velthoven, V., Gumpp, V., Bartelt, S., Ostertag, C., and Nikkhah, G. (2009). Neurosurgical treatment strategies in childhood craniopharyngiomas: is less more? Childs Nerv. Syst. 25, 1419-1427.

Steňo, J., Bízik, I., Steňo, A., and Matejcík, V. (2011). Craniopharyngiomas in children: how radical should the surgeon be? Childs Nerv. Syst. 27, 41-54.

Tian, Z. M., Liu, Z. H., Kang, G. Q., Zhang, Y., Li, S. Y., Chen, X. H., Chui, Y., and Feng, H. (1992). CT-guidedstereotactic injection of radionuclide for treatment of brain tumors. Stereotact. Funct. Neurosurg. 59, 169-173.

Tilgner, J., Herr, M., Ostertag, C., and Volk, B. (2005). Validation of intraoperative diagnoses using smear preparations from stereotactic brain biopsies: intraoperative versus final diagnosis - influence of clinical factors. Neurosurgery 56, 257-265.

Veeravagu, A., Lee, M., Jiang, B., and Chang, S. D. (2010). The role of radiosurgery in the treatment of craniopharyngiomas. Neurosurg. Focus 28, E11.

Yaşargil, M. G., Curcic, M., Kis, M., Siegenthaler, G., Teddy, P. J., and Roth, P. (1990). Total removal of craniopharyngiomas. Approaches and long-term results in 144 patients. J. Neurosurg. 73, 3-11.

Zhao, R., Deng, J., Liang, X., Zeng, J., Chen, X., and Wang, J. (2010). Treatment of cystic craniopharyngioma with phosphorus-32 intracavitary irradiation. Childs Nerv. Syst. 26, 669-674.

Conflict of Interest Statement: The authors declare that the research was conducted in the absence of any commercial or financial relationships that could be construed as a potential conflict of interest.

Received: 30 November 2011; paper pending published: 10 January 2012; accepted: 23 April 2012; published online: 14 May 2012.

Citation: Trippel $M$ and Nikkhah $G$ (2012) Stereotactic neurosurgical treatment options for craniopharyngioma. Front. Endocrin. 3:63. doi: 10.3389/fendo.2012.00063

This article was submitted to Frontiers in Pituitary Endocrinology, a specialty of Frontiers in Endocrinology.

Copyright (C) 2012 Trippel and Nikkhah.

This is an open-access article distributed under the terms of the Creative Commons Attribution Non Commercial License, which permits non-commercial use, distribution, and reproduction in other forums, provided the original authors and source are credited. 